\title{
Factors Affecting Risk Efficiency: A Data Envelopment Approach
}

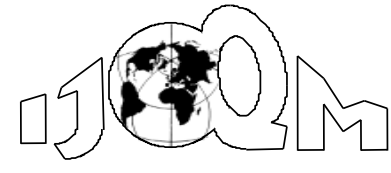

DOI: $10.46970 / 2021.27 .2 .3$

Volume 27, Number 2

June 2021, pp. 127-140

\author{
Kanis Fatama Ferdushi \\ Shahjalal University of Science and Technology \\ (kanis-sta@ sust.edu)
}

Anton Abdulbasah Kamil

Istanbul Gelisim University

(akamil@gelisim.edu.tr)

This paper estimated the two-step process of production risk model which
allows positive and negative marginal risk of production. In addition, a non-
parametric data envelopment based analytical model is developed with a
conjunction of production risk model as a purpose of relevant determinants to
estimate the risk efficiency of the Transplanted AMAN rice farm. The results
indicate that the important variable labor was expected to be risk-reducing,
but it was positively related to risk in the farms of Dhaka (DHR), Chittagong
(CHR), Khulna (KHR), Barishal (BAR) and Rangpur (RANGR) region.

Keywords: Production Risk, Marginal Risk, Data Envelopment, Stochastic

Dominance

\section{Introduction}

The perception of risk has always been existent in the agricultural atmosphere. Production risk becomes an integral part of the decision making by producers. There are many literatures that has enriched the history of agricultural production risk. Production risk model is one of the most vital developments in agriculture. For the first time, Just and Pope $(1979,1978)$ had incorporated effect of input not only in expected output, but also input's variability in production risk model. (Just and Pope 1978) proposed that the marginal risk may be positive, zero and negative in input levels. Several consequential empirical studies of production risk were being studied using Just and Pope's approach and have provided evidence of output risk in agricultural production sectors (Tveteras, Flaten, and Lien 2011; Di Falco and Chavas 2006; Kumbhakar 2002; Griffiths and Anderson 1982; Kim and Pang 2009).

Risk efficiency is a significant aspect of production which has not been adequately accounted before. The risk efficiency is a minimum attainable risk of farm compared to observed risk or to attain maximum expected utility of individuals. The favorable choice of input to minimize risk for an efficient performance means risk efficiency whereas 'expected performance' being a best estimate average performance, 'risk' being 'the possibility of adverse departures from expectations.' The accumulated risk of farm is part of the production plan. By reducing the production risk in farm, farmers can minimize their risk and maximize their yield rate (Harwood et al. 1999; Meuwissen, Huirne, and Hardaker 2001). Farmers as a decision maker, have three choices in dealing successfully with production risks which can be stated as the inherent riskiness of the production process. One, they can control or minimize risk through management practices by doing a better performance of their present status. 
Two, they can reduce production variability by making changes such as diversifying, integrating, applying technology, etc. Three, a farmer can transfer production risk to someone else through contracting, purchasing insurance, etc. (Meuwissen, Huirne, and Hardaker 2001; Flaten et al. 2005) Insurance schemes were supposed as relevant strategies to manage risks. Insurance for crops is not a common picture in developing country like Bangladesh. (Le Bihan, Pardo, and Guillotreau 2013) older oyster farmers were less interested in insurance products. The farmer may continue farming as like before, but it is possible that the farmer can minimize risk through both best input choices and management practices is considered in this paper. Followed by (Tveteros 1999; Tveteras, Flaten, and Lien 2011; Chang and Wen 2011) stochastic dominance criteria were used to mitigate the comparison of distribution of the estimated risk efficiency.

Agricultural sector, especially rice farm of Bangladesh faces production risk in different ways. In between three types of principal rice, Transplanted AMAN (T. AMAN) rice of Bangladesh becomes grown during May-June to November and harvested in December and January and followed by rain fed ecosystem. T. AMAN rice production in Bangladesh is subject to considerable production risk due to rainfed ecosystem, which can be interrupted into output variance as a result of the intensity of input use and systemic weather effects. Basak et al. (2012) projected that population growth rate is two million people per year and will reach 233.2 million by 2050, going by the current trend in Bangladesh. Bangladesh will require more than 55.0 million tons of rice per year to feed its people by the year 2050. According to Basak et al. (2012) T. AMAN rice production is expected to reduce by $1.7 \%, 2.5 \%$, $3.64 \%$ and $5.50 \%$ (base year 2008) in the years 2020, 2030, 2040 and 2050 respectively. In order to get self-sufficiency in rice, Bangladesh will have to continue to expand rice production by raising yields at a rate that is at least equal to population growth until the demand for rice has been stabilized. Our goal is to determine how much production risk farmer can minimize through best input choices in the context of Bangladesh rain fed lowland rice farm (T. AMAN). The commonly followed objectives for this study can be stated as to find out risk efficiency of T. AMAN rice. For the next level to identify those inputs, which supposed to work as a risk increase or decrease components in production. To compare the risk efficiency among the different regions.

\section{Materials}

We have used a data set that contains on production related variable collected to fulfill the framework of the study. Data were collected by the interview method survey through a questionnaire on the year 2018. Only agricultural T. AMAN rice cropping farm was considered in this study. Data were collected immediately after the 'T. AMAN' harvest to minimize errors arising from farmer recall in late November and early December. In the sampling year 2018, favorable weather condition supports all over the country during sowing to harvesting period of the crop. The study design was a multistage cluster sampling to select rice growers or farm household, in which a union was considered as a cluster. The survey was planned to select data under each cluster from randomly selected Village. The selection procedure of sample farm was carried out in three steps. The first step was selecting two districts purposively under each division. Bangladesh is divided into 
seven major administrative regions, called divisions. The second step was a random selection of clusters or Thana from these districts. Two Thanas have been selected under each district ${ }^{5}$. Third step is the selection of Union Parishads under each Thana. The districts covered under AEZ according to BBS (2012b) and are given in Table 1. The sample size was calculated using the following formula given by Islam (2005) from each division $n=z^{2}\left\lfloor P(1-P) / d^{2}\right\rfloor * D_{\text {eff }}$ where $n$ is the size of the sample; $z$ is two-sided normal variate at $95 \%$ confidence level $(1.96) ; P$ is the percentage of indicator; $d$ denotes the precision; $D_{\text {eff }}$ is the design effect. To obtain data on indicators at a $10 \%$ precision and $95 \%$ confidence interval, assuming a design effect of 2.20 and the most conservative estimate of indicator percentage (50\%), the sample size required was 200. Therefore, 200 farm households were required to measure the efficiency of rice growing farmers from each division. A total of 1400 farms were considered for this study for seven different divisions. It is a statistically representative sample. Regional difference brings production variability within farm. Regional difference varies due to farm manager's personal qualification, farming practice, availability of irrigation facility, favourable climate, soil etc. Bangladesh consists of 30 agro-ecological zones (AEZ) and is overlapping with each other. A total number of 7 mutually exclusive regions were considered in the data set. The description of the data sets has been given in Table 1 . The analysis had been carried out using production as the dependent variable.

Table 1 Descriptions of the Variable

\begin{tabular}{|l|l|}
\hline \multicolumn{1}{|c|}{ Variables } & \multicolumn{1}{c|}{ Description } \\
\hline $\begin{array}{l}\text { Production } \\
(\mathrm{kg})\end{array}$ & Total production of T. AMAN during monsoon season year 2018 \\
\hline Area $(\mathrm{ha})$ & The quantity of appropriate land was used for T. AMAN rice farm \\
\hline Labor $($ Person) $)$ & $\begin{array}{l}\text { The number of day labor worked for T. AMAN rice farm, including the } \\
\text { farmer owner and family member }\end{array}$ \\
\hline Seed $(\mathrm{kg})$ & $\begin{array}{l}\text { The quantity of seed was produced by the farmer own self or from the } \\
\text { government. }\end{array}$ \\
\hline Fertilizer $(\mathrm{kg})$ & $\begin{array}{l}\text { The quantity of fertilizer was consumed by the farmer. The fertilizer was } \\
\text { UREA, MP and GIPSAM. We considered combination of all fertilizers. }\end{array}$ \\
\hline $\begin{array}{l}\text { Irrigation Cost } \\
(\text { TK })\end{array}$ & $\begin{array}{l}\text { Total cost for irrigation. Different type of irrigation e.g., deep tube well, } \\
\text { sallow, hand, traditional, canal, and others were considered. }\end{array}$ \\
\hline Pesticide $(T K)$ & $\begin{array}{l}\text { The total cost for pesticide was being used as variable pesticide during the } \\
\text { monsoon season year 2018 }\end{array}$ \\
\hline
\end{tabular}

Note: $\mathrm{Kg}$ represents Kilogram, Ha represents Standard Unit Hectare, TK represents the Value of Money of Bangladesh as Taka.

\section{Methodology}

Our main purpose is to estimation of risk efficiency which in a two-step procedure. First step is to estimation of production risk and next step is to an estimation of risk minimization. 


\section{Step 1: Estimation of Production Risk Model}

According to Just and Pope $(1978,1979)$ the model with heteroscedastic error term can be represented as $y_{i}=f\left(x_{i}, \beta_{i}\right)+h\left(z_{i}, \delta_{i}\right) \varepsilon_{i}$

$f\left(x_{i}, \beta_{i}\right)$ is the mean of production function;

$h\left(z_{i}, \delta_{i}\right)$ is the variance of function or risk function;

$x$ and $z$ are vectors of inputs; The exogenous, stochastic disturbance is $E(\varepsilon)=0$ and $V(\varepsilon)=\sigma^{2}$

Mean output can be represented as

$$
E\left(y_{i}\right)=f\left(x_{i}, \beta_{i}\right)+u_{i}
$$

Variety of output or yield variability can be represented as

$$
V\left(y_{i}\right)=\left[h\left(z_{i}, \delta_{i}\right)\right]^{2} \sigma^{2}
$$

\section{Step 1.1: Estimation of Mean Output}

Mean output as represented through equation (1) can be estimated as follows

$$
Y_{t}=f\left(x_{t} ; \alpha_{t}\right)+u_{t}
$$

to obtain $\alpha_{t}$ and $\hat{u}_{t}=y_{t}-f\left(x_{t} ; \alpha\right)$

Where the vector of inputs $x$ gather area, labor, seed, fertilizer, plough cost, irrigation cost and pesticide.This residual is used to estimate the yield variability. Here, Generalized Moments Method is used to solve the mean output.

\section{Step 2: Estimation of Yield Variability or Risk Model}

Following (Just and Pope 1978, 1979; Kumbhakar 2003; Kumbhakar and Tveterås 2003; Koundouri and Nauges 2005), Equation (2) are used to estimate the variance or risk function is modelled as a Cobb-Douglas (CD) form

$$
\ln \left|\hat{u}_{t}\right|=f\left(\ln x_{t} ; \beta_{t}\right)+\ln \left(v_{t}\right)
$$

Estimation of the equation (2.1) will give us different type of variability for different inputs. In this way yield variability can be obtained for specific or each input variable, further this yield variability will be used to estimate risk minimization.

\section{Step 2.1: Estimation of Production Risk Minimization}

Risk efficiency (RE) is estimated by the following minimization model 


$$
\begin{gathered}
\operatorname{Min}_{\lambda, r_{i}^{*}} G_{i}^{\prime} r_{i}^{*} \\
\text { s.t., } \sum_{j}^{n} Y_{m j} \lambda_{j}-y_{m i} \geq 0 \\
r_{i}^{*}-\sum_{j}^{n} R_{k j} \lambda_{j} \geq 0 \\
N 1^{\prime} \lambda=1 \\
\sum_{j}^{n} \lambda_{j}=1
\end{gathered}
$$

If $G_{i}$ is a vector of yield variability which creates risk for production for the $i^{\text {th }}$ DMU calculated from equation $(2.1) ; r_{i}^{*}$ is the risk minimization vector of the input quantities for the $i^{t h} \mathrm{DMU}$ (which is calculated by linear programming model); $y_{i}$ is the output levels; $R$-is a matrix of input factor affecting rain fed lowland rice yield variability. $N 1$ is a vector of one included for Variable Return to Scale (VRS) model $\lambda$ is the weight of the $j^{\text {th }}$ farm.

\section{Step 2.2: Estimation of Technical Efficiency}

Technical efficiency (TE) is estimated by the following model

$$
\begin{aligned}
& \operatorname{Min}_{\phi_{i}, \lambda_{j}} \phi_{i} \\
& \text { s.t., } \sum_{j}^{n} Y_{m j} \lambda_{j}-y_{m i} \geq 0 \\
& \phi_{i} r_{k i}-\sum_{j}^{n} R_{k j} \lambda_{j} \geq 0 \\
& N 1^{\prime} \lambda=1 \\
& \sum_{j}^{n} \lambda_{j}=1
\end{aligned}
$$

Where $i=1,2, \ldots, m$ inputs $; j=1,2, \ldots, n$ farm unit. $\phi_{i}$ is the proportional increase in outputs could be obtained by the $i^{\text {th }}$ farm unit given input vector; $y_{i}$ denotes output vector; $r_{k i}$ denotes input vector; $R$ is a matrix of input factor affecting rain fed low land rice yield variability. $N 1$ is a vector of one included for Variable Return to Scale (VRS) model $\lambda$ is the weight of the $j^{\text {th }}$ farm unit.

Risk Efficiency

$$
R E=\frac{G_{i}^{\prime} r_{i}^{*}}{G_{i}^{\prime} r_{i}}
$$




$$
\text { Allocative Efficiency } \quad A E=\frac{R E}{T E}
$$

Equation 3, 4, 5, and 6 were estimated using the software DEAP 2.1(Coelli, 1996) for different regional farms namely DHR, CHR, RAJR, KHR, BAR, SYR, and RANGR.

\subsection{Estimation Procedure of Risk Minimization}

Just and Pope (JP) model can be estimated in two step procedure. Translog, Linear Quadratic and Generalized Method of Moments (GMM) and CD had been used in most econometric specifications. From an economic standpoint, the GMM estimator is constructed from first and second order moment condition and can be easily obtained from Wooldridge (2005) the system's equations. The presentation of GMM permits us to handle more appropriately regional heterogeneity. The GMM estimation procedure was considered in this study. (Koundouri and Nauges 2005; Gardebroek, Chavez, and Lansink 2010; Farnsworth and Moffitt 1981) applied JP production model with two step procedure of GMM estimation. Following Antle (1983), Di Falco and Chavas (2006) applied weighted ordinary least square (OLS) to solve the heteroscedaticity.

\subsection{Hypothesis}

In order to show the robustness of DEA, statistical test of hypothesis involved in this study is assume that there exist differences in efficiency among the farms of DHR, CHR, RAJR, KHR, BAR, SYR, and RANGR regions.

\subsection{Stochastic Dominance Criterion for Risk Efficiency}

The final step of the analysis is to compare the estimated risk efficiency in between seven regions or seven different groups of firms. A nonparametric test of Kruskal Wallis was carried to observe the significance differences among seven different regions. There was a statistically significant difference between the risk efficiency in different groups, the chi square test statistics was 270.052 with degrees of freedom (df) 6 and p-value was 0.000 which was less than 0.5 . The stochastic dominance condition was followed by (Chen and Song 2008; Chang and Wen 2011) to identify the stochastically dominance group. The stochastic dominance analysis usually is developed to rank the outcomes. The ranking is based on Cumulative Density Functions (CDF).

The first order stochastic dominance (FOSD) rules are discussed followed by Hadar and Russell (1971) and Hanoch and Levy (1969). It is assumed that the regional efficiency is associated with the distribution of risk efficiency, and that CDF of risk efficiencies are given by DHR (RE) and CHR (RE) for farmers of Dhaka region and Chittagong region respectively. The risk efficiency of the farmers of DHR work dominates its counterpart in the concept of FOSD, if farm in DHR first order stochastically dominates the farm of $\mathrm{CHR}$, i.e. the rate of lower risk efficiency in CHR is higher than in DHR.

$$
C D F_{D H R}(R E) \leq C D F_{C H R}(R E), \quad \forall R E \subseteq R, \quad 0 \leq R E \leq 1
$$


The stochastic dominance criterion will show which regional household farm is stochastically dominant by others regional farm.

\section{Results and Discussion}

Two hypotheses have been opted to test the data. First, there are no differences in between the production of the different regional rice farm. Second, there are no heteroskedasticity across the Bangladesh regional rice farms. First hypothesis had been tested through the Levene test. The null hypothesis was mentioned about variability in production rejected $(P=0.000)$ at $1 \%$ level of significance. The different heteroskedasticity tests had been selected to mitigate the second hypothesis are being presented in Table 2. The tests suggest that heteroskedasticity exists in the data set. The estimates of production risk or yield variability are given in Table 3 . The sign of the risk functions indicates whether the inputs are risk increasing or decreasing. In case of positive sign, it is assumed that the inputs are risk increasing and vice versa. In the Dhaka region, labor, labor wage, fertilizer price and pesticide were strongly positive about the risk which is statistically significant at the $1 \%$ level of significance. The coefficient of seed was showing positive to risk but insignificant. The coefficient of pesticide and fertilizer were negatively associated with risk and highly statistically significant. The variables labor and fertilizer were found risk increasing and reducing respectively in Dhaka region contradicts the result of Picazo-Tadeo and Wall (2011). Fertilizer was found to be risk- increasing in other studies of rice production (Villano and Fleming 2006; Smith and Umali 1985; Pandey 2004). Area was ascertained to be risk-reducing same as (Picazo-Tadeo and Wall 2011; Gardebroek, Chavez, and Lansink 2010). Area was found risk increasing by (Villano and Fleming 2006). Horowitz and Lichtenberg (1994) showed that pesticide is not necessarily need to be risk -reducing but in Dhaka regional rice farm, pesticide was working as risk-reducing input. Horowitz and Lichtenberg (1994) also showed pesticide may likely be risky-increasing in the conditions of crop growth. In Chittagong region, the coefficient of area, wage, fertilizer price were showed negative sign and statistically significant at the $1 \%$ level of significance.

Picazo-Tadeo and Wall (2011) found that land was risk reducing in Spanish rice farms. A similar result was found in the Chittagong regional rice farms. The sign of the coefficient of labor, seed, seed price, fertilizer, cost of plough and pesticide were positive. The results indicate that those variables were generating risk in output of production but statistically insignificant. Fertilizer was found risk increasing input by (Gardebroek, Chavez, and Lansink 2010) on Dutch organic farms same as CHR rice farms. Seed was risk-increasing as same conclusion with Picazo-Tadeo and Wall (2011).

In the Rajshahi region, the area was showing negative sign which indicates that was risk reducing. The coefficient of the input, area, labor, wage, seed, seed price, fertilizer, fertilizer price, plough cost, irrigation cost and pesticide were negative and highly statistically significant at the $1 \%$ level of significance except wage which was statistically significant at the $5 \%$ level of significance. The results draw the conclusion that all inputs were beneficiary for production in RAJR rice farms. 
Table 2 Heterogeneity Test

\begin{tabular}{|c|c|c|c|c|c|c|c|}
\hline $\begin{array}{c}\text { Heteroscedasticity } \\
\text { Test }\end{array}$ & DHR & CHR & RAJR & KHR & BAR & SYR & RANGR \\
\hline & $\begin{array}{l}\text { Chi-S.(P - } \\
\text { value) }\end{array}$ & $\begin{array}{c}\text { Chi-S.(P - } \\
\text { value) }\end{array}$ & $\begin{array}{c}\text { Chi-S.(P - } \\
\text { value) }\end{array}$ & $\begin{array}{c}\text { Chi-S.(P - } \\
\text { value) }\end{array}$ & $\begin{array}{c}\text { Chi-S.(P - } \\
\text { value) }\end{array}$ & $\begin{array}{c}\text { Chi-S.(P - } \\
\text { value) }\end{array}$ & $\begin{array}{c}\text { Chi-S.(P - } \\
\text { value) }\end{array}$ \\
\hline \multicolumn{8}{|l|}{ ARCH Test } \\
\hline$e_{t}^{2} \quad$ on $\quad \hat{Y}_{t}$ & $2.922(0.08)$ & $30.264(0.00)$ & $10.856(0.000)$ & $0.244(0.62)$ & $0.21(0.88)$ & $16.654(0.000)$ & $0.18(0.36)$ \\
\hline$e_{t}^{2}$ on $\log \left(\hat{Y}_{t}^{2}\right)$ & $3.975(0.04)$ & $0.296(0.58)$ & $3.131(0.0768)$ & $0.034(.85)$ & $.514(0.47)$ & $5.049(0.024)$ & $0.728(0.39)$ \\
\hline$e_{t}^{2} \quad$ on $\quad e_{t-1}^{2}$ & $21.698(0.00)$ & $11.704(0.00)$ & $6.824(0.009)$ & $42.341(0.00)$ & $66.151(0.00)$ & $41.469(0.000)$ & $85.887(0.00)$ \\
\hline \multicolumn{8}{|l|}{ Harvey Test } \\
\hline$e_{t}^{2}$ on $X_{t}$ & $27.191(0.00)$ & $22.874(0.00)$ & $12.225(0.031)$ & $10.00(0.07)$ & $4.721(0.45)$ & $12.271(0.31)$ & $5.998(.30)$ \\
\hline $\begin{array}{l}\text { Breusch Pagan Test } \\
\text { (SSR): } e_{t}^{2} \text { on } X_{t}\end{array}$ & $28.066(0.00)$ & $103.771(0.00)$ & $80.697(0.000)$ & $5.219(0.389)$ & $7.514(0.18)$ & $23.826(0.000)$ & $4.711(0.45)$ \\
\hline \multicolumn{8}{|l|}{$\begin{array}{l}\text { White Test: } \\
e_{t}^{2} \text { on } X, X_{k}^{2}\end{array}$} \\
\hline CHOW TEST & $102.33(0.00)$ & $72.433(0.000)$ & $82.116(0.00)$ & $83.179(0.00)$ & $63.210(0.00)$ & $95.309(0.00)$ & $81.084(0.00)$ \\
\hline $\begin{array}{l}\text { GOLDFELD- } \\
\text { QUANDT }\end{array}$ & $1.212(0.00)$ & $1.389(0.05)$ & $1.084(0.000)$ & $1.315(0.93)$ & $1.012(0.478)$ & $0.774(0.108)$ & $1.237(0.152)$ \\
\hline
\end{tabular}

Note: The GQ Test Statistic is F-distributed with $\{n l-K\}$ (Coelli 1996) and $\{n 2-K\}$ Degrees of Freedom, where $n 1$ and $n 2$ are the Number of Observations in the Two Subsamples and $K$ is the Number of Parameters in the Model

Plough cost and irrigation cost were risk-reducer. Generally risk averse producer chooses plough and irrigation to their farms to reduce the vulnerability Hurley (2010). In Khulna region, area, seed and fertilizer were negative and highly statistically significant. In Khulna region, labor, wage, seed price, fertilizer price, plough cost, irrigation cost and pesticide were all positive and statistically highly significant. Labor was risk-increasing as like DHR rice farms. In Barisal region, only two variable area and seed were negatively associated with production and statistically significant. All other variables (labor, wage, seed price, fertilizer, fertilizer price, plough cost and irrigation cost) were positively associated with the production process in Barisal regional farms. Seed was risk-decreasing input as like KHR and CHR. In Sylhet region, area, labor, wage, fertilizer, plough cost and pesticide were indicating risk reducing variable in the production process. Seed, fertilizer price and irrigation cost were positive and significant and working to decrease the risk efficiency. Most of the rice farms in SYR are small scale farms. Small scale farmer had less possibility to weeds and fungi affect rice plants PicazoTadeo and Wall (2011). In Rangpur region labor, wage, seed price, plough cost and irrigation costs were positive. These results were positively correlated with the production and also statistically significant at the $1 \%$ level of significance. On the other hand, area, seed and pesticide were negatively associated with production and 
also significant at the $1 \%$ level of significance. Two input variables fertilizer and fertilizer price were positively associated with production but insignificant. Fertilizer and labor were risk-increasing as shown by Villano, O'Donnell, and Battese (2005) in case of Philippines rice farms.

Table 3 Estimation of Yield Variability for Different Regional Farm

\begin{tabular}{|l|c|c|c|c|c|c|c|}
\hline Variable & DHR & CHR & RAJR & KHR & BAR & SYR & RANGR \\
\hline & \multirow{2}{*}{ Coefficient } & Coefficient & Coefficient & Coefficient & Coefficient & Coefficient & Coefficient \\
\hline \multirow{2}{*}{ Area } & $-0.696 \mathrm{E}-$ & $-0.388 \mathrm{E}-$ & $-0.271 \mathrm{E}-$ & $-0.555 \mathrm{E}-$ & $-0.309 \mathrm{E}-$ & $-0.683 \mathrm{E}-$ & $-0.612 \mathrm{E}-$ \\
& $30^{*}(-3.17)$ & $30^{*}(-14.55)$ & $20^{*}(-6.34)$ & $15^{*}(-4.21)$ & $16^{* *}(-2.10)$ & $22^{*}(-4.03)$ & $13^{*}(-3.41)$ \\
\hline \multirow{2}{*}{ Labor } & $0.537 \mathrm{E}-$ & $0.317 \mathrm{E}-$ & $-0.375 \mathrm{E}-$ & $0.115 \mathrm{E}-$ & $0.146 \mathrm{E}-$ & $-0.107 \mathrm{E}-$ & $0.577 \mathrm{E}-$ \\
& $30^{*}(7.78)$ & $11(1.14)$ & $28^{*}(-17.98)$ & $28^{*}(7.82)$ & $27^{*}(10.21)$ & $28^{*}(-8.61)$ & $28^{*}(3.55)$ \\
\hline \multirow{2}{*}{ Seed } & $0.279 \mathrm{E}-$ & $0.167 \mathrm{E}-$ & $-0.767 \mathrm{E}-$ & $-0.279 \mathrm{E}-$ & $-0.894 \mathrm{E}-$ & $0.893 \mathrm{E}-$ & $-0.847 \mathrm{E}-$ \\
& $32(0.95)$ & $11(1.25)$ & $28^{*}(-4.84)$ & $29^{*}(-19.54)$ & $28^{*}(-3.20)$ & $10^{*}(3.16)$ & $30^{*}(-4.41)$ \\
\hline \multirow{2}{*}{ Fertilizer } & $-0.367 \mathrm{E}-$ & $0.153 \mathrm{E}-$ & $-0.234 \mathrm{E}-$ & $-0.443 \mathrm{E}-$ & $0.177 \mathrm{E}-$ & $-0.249 \mathrm{E}-$ & $0.387 \mathrm{E}-$ \\
& $30^{*}(-5.88)$ & $11(1.27)$ & $15^{*}(-2.69)$ & $10^{*}(-5.27)$ & $27^{*}(4.36)$ & $18^{*}(-4.84)$ & $14(1.93)$ \\
\hline Plough & $-0.498 \mathrm{E}-$ & $0.167 \mathrm{E}-$ & $-0.125 \mathrm{E}-$ & $0.289 \mathrm{E}-$ & $0.402 \mathrm{E}-$ & $-0.204 \mathrm{E}-$ & $0.277 \mathrm{E}-$ \\
Cost & $12^{*}(-5.21)$ & $11(1.14)$ & $28^{*}(-4.29)$ & $28^{*}(5.78)$ & $28^{*}(2.98)$ & $30^{*}(-4.88)$ & $28^{*}(3.57)$ \\
\hline Irrigation & $0.782 \mathrm{E}-$ & $0.267 \mathrm{E}-$ & $-0.179 \mathrm{E}-$ & $0.405 \mathrm{E}-$ & $0.764 \mathrm{E}-$ & $0.438 \mathrm{E}-$ & $0.933 \mathrm{E}-$ \\
Cost & $31^{* *}(1.81)$ & $30^{*}(4.68)$ & $28^{*}(-10.98)$ & $31^{*}(3.50)$ & $29^{*}(9.03)$ & $28^{*}(3.85)$ & $30^{*}(3.92)$ \\
\hline \multirow{2}{*}{ Pesticide } & $-0.367 \mathrm{E}-$ & $0.495 \mathrm{E}-$ & $-0.162 \mathrm{E}-$ & $0.112 \mathrm{E}-$ & $0.930 \mathrm{E}-$ & $-0.418 \mathrm{E}-28(-$ & $-0.174 \mathrm{E}-$ \\
& $30^{*}(-5.93)$ & $11(1.02)$ & $28^{*}(-6.03)$ & $29^{*}(6.26)$ & $15^{*}(5.89)$ & $1.11)$ & $32^{*}(-3.87)$ \\
\hline
\end{tabular}

\subsection{Assessing Efficiency}

Table 4 showed the descriptive statistical measure for technical, allocative and risk efficiency for every 200 farms in DHR, CHR, RAJR, KHR, BAR, SYR and RANGR. Risk efficiency in different region are varied from 0.237 to 0.5068 which showed that farm are reducing a very small amount of risk and harmful for agricultural farm. That is, DMU of that region should be able to reduce the risk of production of all inputs. DMU's of these seven regions should be able to reduce risk of production, $63.1 \%, 57.36 \%, 59.55 \%, 49.32 \%, 70.11 \%, 76.24 \%$ and $71.1 \%$ for DHR, CHR, RAJR, KHR, BAR, SYR and RANGR respectively.

The skewness values of allocative and risk efficiency indicated that all distributions were right-tailed, i.e., several observations are by far higher than the others, but skewness values of technical efficiency indicated all are left tailed. The distribution of risk efficiency in different region of Bangladesh is summarized in the Figure 1.

\subsection{VRS Risk Efficiency Correlation Test}

In order to show the robustness of DEA, statistical test of hypothesis involved in this study is as follows:

$H_{0}$ : The efficiency score of $i_{1}^{t h}(D H R)$ farm=The efficiency score of $i_{2}^{\text {th }}(C H R)$ farm=The efficiency score of $i_{3}^{\text {th }}(R A J R)$ farm=The efficiency score of 
$i_{4}^{\text {th }}(K H R)$ farm $=$ The efficiency score of $i_{5}^{t h}(B A R)$ farm=The efficiency score of $i_{6}^{\text {th }}(S Y R)$ farm=The efficiency score of $i_{7}^{\text {th }}(R A N G R)$ farm

$H_{1}$ :There exists differences in between the efficiency of different regional farms of DHR, CHR, RAJR, KHR, BAR, SYR and RANGR.

Table 4 Descriptive Statistics of VRS Risk Efficiency, Technical Efficiency and Allocative Efficiency

\begin{tabular}{|c|c|c|c|c|c|c|}
\hline Efficiency & Mean & Standard Deviation & Kurtosis & Skewness & Minimum & Maximum \\
\hline \multicolumn{7}{|c|}{ Technical Efficiency } \\
\hline TE_DHR & .8892 & .1349 & 1.138 & -1.194 & .33 & 1.000 \\
\hline TE_CHR & .8420 & .2150 & -.281 & -1.067 & .325 & 1.000 \\
\hline TE_RAJR & .8474 & .1928 & .361 & -1.162 & .190 & 1.000 \\
\hline TE_KHR & .8552 & .1862 & .587 & -1.233 & .296 & 1.000 \\
\hline TE_BAR & .6793 & .3019 & -1.548 & -.213 & .152 & 1.000 \\
\hline TE_SYR & .7389 & .2763 & -1.010 & -.645 & .148 & 1.000 \\
\hline TE_RANGR & .8443 & .1622 & .119 & -.964 & .383 & 1.000 \\
\hline \multicolumn{7}{|c|}{ Allocative Efficiency } \\
\hline AE_DHR & .4080 & .1582 & 5.479 & 2.137 & .19 & 1.000 \\
\hline AE_CHR & .4990 & .2315 & -1.162 & 0.349 & 0.156 & 1.000 \\
\hline AE_RAJR & .4471 & .2495 & -.614 & .747 & .067 & 1.000 \\
\hline AE_KHR & .5829 & .1706 & .341 & .014 & .036 & 1.000 \\
\hline AE_BAR & .3664 & .1899 & 1.950 & 1.410 & .077 & 1.000 \\
\hline AE_SYR & .3138 & .2014 & 1.261 & 1.032 & .030 & 1.000 \\
\hline AE_RANGR & .3378 & .1495 & 5.696 & 1.854 & .015 & 1.000 \\
\hline \multicolumn{7}{|c|}{ RE Risk Efficiency } \\
\hline RE_DHR & .3685 & .1742 & 4.611 & 1.976 & .09 & 1.000 \\
\hline RE_CHR & .4264 & .2471 & -.857 & .633 & .134 & 1.000 \\
\hline RE_RAJR & .4045 & .2762 & -.763 & .706 & .047 & 1.000 \\
\hline RE_KHR & .5068 & .2059 & -.298 & .198 & .036 & 1.000 \\
\hline RE_BAR & .2589 & .2190 & 2.623 & 1.767 & .048 & 1.000 \\
\hline RE_SYR & .2376 & .2086 & 2.567 & 1.591 & .030 & 1.000 \\
\hline RE_RANGR & .2890 & .1584 & 6.061 & 2.061 & .012 & 1.000 \\
\hline
\end{tabular}

Correlation coefficients between efficiency findings for the seven different regions in Bangladesh are reported in Table 5. There is no strong positive correlations appear between regional efficiency. Weak correlation exists in between RE_CHR and RE_RAJR, RE_CHR and RE_SYR, RE_RAJR and RE_SYR. Surprising negative 
correlation appears between RE_DHR and RE_KHR, RE_DHR and RE_BAR, RE_CHR and RE_KHR, RE_CHR and RE_BAR, RE_RAJR.

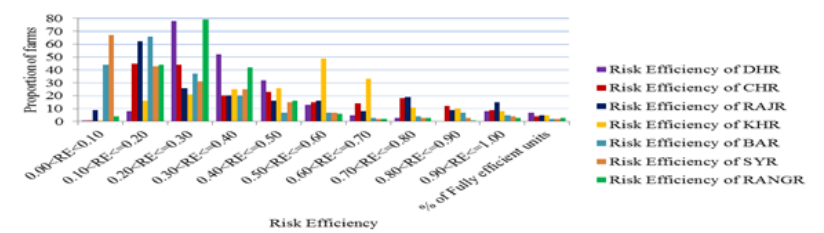

Figure 1 The Distribution of Risk Efficiency in Different Region in Bangladesh

Table 5 Correlation Coefficient for Selected Risk Efficiency Measure

\begin{tabular}{|l|c|c|c|c|c|c|c|}
\hline Risk Efficiency & RE_DHR & RE_CHR & RE_RAJR & RE_KHR & RE_BAR & RE_SYR & RE_RANGR \\
\hline RE_DHR & 1 & & & & & & \\
\hline RE_CHR & $0.444^{* * *}$ & 1 & & & & & \\
\hline RE_RAJR & $0.469^{* * *}$ & $0.585^{* * *}$ & 1 & & & & \\
\hline RE_KHR & $-0.343^{* * *}$ & $-0.525^{* * *}$ & $-0.448^{* * *}$ & 1 & & & \\
\hline RE_BAR & $-0.200^{* *}$ & $-0.432^{* * *}$ & $-0.390^{* *}$ & $0.215^{* *}$ & 1 & & \\
\hline RE_SYR & $0.393^{* * *}$ & $0.537^{* * *}$ & $0.507^{* * *}$ & $-0.389^{* * *}$ & $-0.391^{* * *}$ & 1 & \\
\hline RE_RANGR & 0.126 & $0.251^{* *}$ & $0.237^{* *}$ & -0.091 & $-0.251^{* *}$ & $0.168^{* * *}$ & 1 \\
\hline
\end{tabular}

Note. ${ }^{* *}, * *, *$ are Significance Level at 1\%, 5\%, and 10\% Respectively

\subsection{Stochastic Dominance Criterion}

In case of FOSD, for any CDF point the risk efficiency will be high and continuously increasing. Figure plots the associated CDF of risk efficiency of seven different regions in Bangladesh for sampling years 2018, assuming a normal distribution. All $\mathrm{CDF}$ of risk efficiency are depicted in a single Figure 2 to compare among regions.

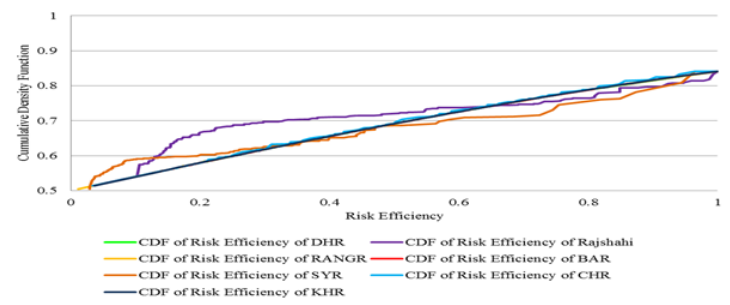

Figure 2 Cumulative Density Function Against Risk Efficiency in Seven Region

\section{Conclusions}

This paper developed a data envelopment based analytical model with a conjunction of production risk model as a purpose of relevant determinants to estimate the risk efficiency of the Transplanted AMAN rice farm. It compares the production risk and risk efficiency of $\mathrm{T}$. AMAN rice farms which varies regionally in Bangladesh. The relative technical efficiency was observed very high compared to allocative and risk 
efficiency. It revealed that, farmers voluntarily accepted the risk. There were several reasons on behind of such act. First, the input choices, i.e., how much fertilizer must use on their farm. Second, farmers cannot irrigate their crops even though they face the risk of inadequate rainfall or drought because of their lack of capital. Unwillingly, farmers are accepting risk although they are risk averse. Subsidized must be given to farmers by the government for the irrigation cost. Bangladesh is a labor surplus country and labor wage according to regional basis was very low for DHR, CHR, RAJR, KHR, BAR and SYR considered as inadequate. In this way, automatically labor and wage inputs making risk into production technology. During 2018 the farmer didn't face any extreme climate erratic condition. Although the success followed by transplanting rice production in the agricultural sector, the country still faces many challenges due to forecast climate change impacts and a continuously growing population.

\section{References}

1. Abedullah and Pandey, Sushil. (2004), "Risk and Fertilizer Use in the Rainfed Rice Ecosystem of Tarlac, Philippines", Journal of Agricultural and Applied Economics, Vol. 36 (01), pp. 241-250.

2. Basak, Jayanta Kumar, M Ashraf Ali, Jiban Krishna Biswas, and Nazrul Islam. (2012), "Effects of Increasing Temperature and Population Growth on Rice Production in Bangladesh: Implications for Food Security", Bangladesh Rice Journal, Vol. 16 (1), pp. 67-75.

3. Chang, Hung-Hao, and Fang- I. Wen. (2011), "Off-farm work, technical efficiency, and rice production risk in Taiwan", Agricultural Economics, Vol. 42 (2), pp. 269-278.

4. Chen, Zhuo, and Shunfeng Song. (2008), "Efficiency and technology gap in China's agriculture: A regional meta-frontier analysis", China Economic Review, Vol. 19 (2), pp. 287-296.

5. Coelli, Tim. (1996), "A guide to FRONTIER version 4.1: A computer program for stochastic frontier production and cost function estimation", CEPA Working Papers.

6. Di Falco, Salvatore, and Jean-Paul Chavas. (2006), "Crop genetic diversity, farm productivity and the management of environmental risk in rainfed agriculture", European Review of Agricultural Economics, Vol. 33 (3), pp. 289314.

7. Farnsworth, Richard L, and L Joe Moffitt. (1981), "Cotton production under risk: an analysis of input effects on yield variability and factor demand", Western Journal of Agricultural Economics, Vol. 6 (2), pp. 155-163.

8. Flaten, O., G. Lien, M. Koesling, P. S. Valle, and M. Ebbesvik. (2005), "Comparing risk perceptions and risk management in organic and conventional dairy farming: empirical results from Norway", Livestock Production Science, Vol. 95 (1-2), pp. 11-25.

9. Gardebroek, Cornelis, María Daniela Chavez, and Alfons Oude Lansink. (2010), "Analysing Production Technology and Risk in Organic and Conventional Dutch Arable Farming using Panel Data", Journal of Agricultural Economics, Vol. 61 (1), pp. 60-75. 
10. Griffiths, William E., and Jock R. Anderson. (1982), "Using Time-Series and Cross-Section Data to Estimate a Production Function with Positive and Negative Marginal Risks", Journal of the American Statistical Association, Vol. 77 (379), pp. 529-536.

11. Hadar, Josef, and William R Russell. (1971), "Stochastic dominance and diversification", Journal of Economic Theory, Vol. 3 (3), pp. 288-305.

12. Hanoch, Giora, and Jerusalem H Levy. (1969), "The efficiency analysis of choices involving risk", The Review of Economic Studies, Vol. 36 (3), pp. 335346.

13. Harwood, Joy L, Richard Heifner, Keith Coble, Janet Perry, and Agapi Somwaru. (1999), Managing risk in farming: concepts, research, and analysis, US Department of Agriculture, Economic Research Service.

14. Horowitz, John K, and Erik Lichtenberg. (1994), "Risk-reducing and risk-increasing effects of pesticides", Journal of Agricultural Economics, Vol. 45 (1), pp. 82-89.

15. Hurley, Terrance M. (2010), "A Review of Agricultural Production Risk in Developing World. Harvest Choice: Better Chioces, Better Lives”, Working Papers 188476, Harvest Choice.

16. Just, Richard E., and Rulon D. Pope. (1978), "Stochastic specification of production functions and economic implications", Journal of Econometrics, Vol. 7 (1), pp. 67-86.

17. Just, Richard E., and Rulon D. Pope. (1979), "Production Function Estimation and Related Risk Considerations", American Journal of Agricultural Economics, Vol. 61 (2), pp. 276-284.

18. Kim, Man-Keun, and Arwin Pang. (2009), "Climate change impact on rice yield and production risk", Journal of Rural Development, Vol. 32 (2), pp. 17-29.

19. Koundouri, Phoebe, and Celine Nauges. (2005), "On production function estimation with selectivity and risk considerations", Journal of Agricultural and Resource Economics, Vol. 30 (3), pp. 597-608.

20. Kumbhakar, Subal C. (2002), "Specification and Estimation of Production Risk, Risk Preferences and Technical Efficiency", American Journal of Agricultural Economics, Vol. 84 (1), pp. 8-22.

21. Le Bihan, VÉRonique, Sophie Pardo, and Patrice Guillotreau. (2013), "Risk Perception and Risk Management Strategies of Oyster Farmers", Marine Resource Economics, Vol. 28 (3), pp. 285-304.

22. Meuwissen, MPM, RBM Huirne, and JB Hardaker. (2001), "Risk and risk management: an empirical analysis of Dutch livestock farmers", Livestock Production Science, Vol. 69 (1), pp. 43-53.

23. Picazo-Tadeo, Andrés J., and Alan Wall. (2011), "Production risk, risk aversion and the determination of risk attitudes among Spanish rice producers", Agricultural Economics, Vol. 42 (4), pp. 451-464.

24. Smith, Joyotee, and Gloria Umali. (1985), "Production risk and optimal fertilizer rates: a random coefficient model", American Journal of Agricultural Economics, Vol. 67 (3), pp. 654-659.

25. Tveteras, Ragnar, Ola Flaten, and Gudbrand Lien. (2011), "Production risk in multi-output industries: estimates from Norwegian dairy farms", Applied Economics, vol. 43 (28), pp. 4403-4414. 
26. Tveteros, Ragnar. (1999), "Production Risk and Productivity Growth: Some Findings for Norwegian Salmon Aquaculture", Journal of Productivity Analysis, Vol. 12 (2), pp. 161-179.

27. Villano, Renato A, Christopher J O'Donnell, and George E Battese. (2005), An Investigation of Production Risk, Risk Preferences and Technical Efficiency: Evidence from Rainfed Lowland Rice Farms in the Philippines. Working Papers 12953, University of New England, School of Economics.

28. Villano, Renato, and Euan Fleming. (2006), "Technical Inefficiency and Production Risk in Rice Farming: Evidence from Central Luzon Philippines", Asian Economic Journal, Vol. 20 (1), pp. 29-46.

29. Wooldridge, Jeffrey M. (2005), "Simple solutions to the initial conditions problem in dynamic, nonlinear panel data models with unobserved heterogeneity", Journal of applied econometrics, Vol. 20 (1), pp. 39-54.

\section{About Our Authors}

Kanis Fatama Ferdushi is Assistant professor in Statistics at Shahjalal University of Science and Technology, Sylhet, Bangladesh, graduated with distinction in 2003 in Statistics at the Shahjalal University of Science and Technology. In 2004 she has got Master of Science in Statistics from the same University. In 2014 she has got Ph. D. in Statistics at the Universiti Sains Malaysia. Her research topics mainly focus on Climate Change, Biostatistics and Econometrics.

Anton Abdulbasah Kamil is Professor at the Istanbul Gelisim University (Turkey), graduated in Statistics from the Padjadjaran University, Bandung, Indonesia in 1988, $\mathrm{He}$ has got Master of Science in Applied Statistics with minor Agricultural Economics from IPB University, Bogor, Indonesia in 1993, and received his Ph. D. in Econometrics at the University of Economics, Prague, Czech Republic in 1998. His current research interests include applied statistics, applied econometrics, operations research, with a specific focus on optimization, data envelopment analysis and stochastic frontier analysis. 